\title{
La asignatura de Lengua y Cultura Ch'ol en secundarias de Tabasco, México y la semántica contradictoria de la educación intercultural
}

\section{Susana Ayala Reyes}

\author{
Departamento de Investigaciones Educativas del Cinvestav \\ (iD) https://orcid.org/000o-0003-2676-0254 \\ Correo electrónico: sareyes@cinvestav.mx
}

Recibido:

11 de abril de 2021 Aceptado:

17 de agosto de 2021

doi: 10.34096/runa.v43i1.10057

\section{Resumen}

En este artículo expongo el proceso de creación e implementación de la asignatura de Lengua y Cultura Indígena ch'ol dirigida a los estudiantes de secundaria en Tabasco e impulsado por la Coordinación General de Educación Intercultural y Bilingüe (CGEIB) de la Secretaría de Educación Pública (SEP) en México. A partir de este caso, analizo las continuidades y las contradicciones semánticas en los discursos torno a la educación intercultural y bilingüe en las reformas educativas de 2000 a 2018. Enlazo datos documentales y etnográficos para estudiar sus consecuencias en tres escalas de práctica política y cuestiono por qué, a pesar de haberse proclamado que la educación intercultural es para todos, en los hechos se dirige exclusivamente a la población categorizada como indígena.

The subject of Ch'ol language and culture in secondary schools in Tabasco, Mexico, and the contradictory semantics of intercultural and bilingual education

\begin{abstract}
In this article, I present the process of creation and implementation of the subject of Ch'ol indigenous language and culture for secondary school students in Tabasco and promoted by the General Coordination of Intercultural and Bilingual Education (CGEIB) of the Ministry of Public Education (SEP) in Mexico. From this case, I analyze the continuities and semantic contradictions in the discourses around Intercultural and Bilingual Education in the
\end{abstract}

Key Words

Intercultural bilingual education; Educational reforms; Language policies; Discourse analysis

\section{Palabras clave}

Educación intercultural bilingüe; Reformas educativas; Políticas lingüísticas; Análisis del discurso 
educational reforms from 2000 to 2018. I combine documentary and ethnographic data to study its consequences on three scales of political practice and question why, despite the proclamation that intercultural education is for all, in fact it is exclusively aimed at the population categorized as indigenous.

\section{O tema da língua e cultura Ch'ol nas escolas secundárias de Tabasco, México, e a semântica contraditória da educação intercultural}

\section{Resumo}

Palavras-chave

Educação bilíngüe intercultural; Reformas educativas; Políticas lingüísticas; Análise do discurso
Neste artigo apresento o processo de criação e implementação do tema da língua e cultura indígena Ch'ol destinado aos estudantes do ensino médio em Tabasco e promovido pela Coordenação Geral de Educação Intercultural e Bilíngüe (CGEIB) do Ministério de Educação Pública (SEP) do México. A partir deste caso, analiso as continuidades e contradições semânticas nos discursos em torno da Educação Intercultural e Bilíngüe nas reformas educacionais de 2000 a 2018. Eu ligo dados documentais e etnográficos para estudar suas consequências em três escalas de prática política e questiono por que, apesar da proclamação de que a educação intercultural é para todos, na verdade ela é destinada exclusivamente à população categorizada como indígena.

\section{Introducción}

El término interculturalidad tiene ya larga historia, tanto en México como en otros países. La categoría fue usada en el siglo XX por Gonzalo Aguirre Beltrán (1991-1955), principal teórico del indigenismo posrevolucionario mexicano, para señalar que eran interculturales las regiones geográficas en donde grupos que él categorizaba como indios y mestizos establecían relaciones de coexistencia y simbiosis económica y social. No obstante, la propuesta de Educación Intercultural y Bilingüe (EIB) no se oficializó en el discurso político sino hasta 1997. De 2000 a 2018 se promulgaron cuatro reformas educativas que mencionan la EIB. En este artículo reflexiono sobre los sentidos y las contradicciones en los discursos, y al mismo tiempo propongo que tienen una semántica continuada basada en la premisa de las relaciones entre dos grupos culturales distintos. Para ello presento, primero, el caso de los sucesivos intentos de implementar la asignatura de Lengua y Cultura Indígena Ch'ol en el estado de Tabasco, al sureste de México.

Los datos que presento son registros que hice en notas etnográficas, libretas de trabajo, entrevistas registradas por escrito y audiograbación y observaciones en campo de 2009 a 2012, periodo durante el que trabajé en el proyecto de la asignatura. De 2014 a 2021 realicé entrevistas y visitas en algunas localidades. Articulo esos datos con los discursos de documentos normativos y materiales didácticos con el fin de relatar desde una perspectiva etnográfica e histórica reciente los discursos y actos políticos relativos a la EIB. Muestro así, los procesos discursivos que impulsaron la asignatura y posteriormente provocaron su abandono. En ellos analizo qué conceptualizaciones e ideologías están 
implícitas en las nociones sobre los destinatarios de estas políticas, la cultura y la educación bilingüe subyacentes en los discursos federales. Finalmente, hago un balance de los efectos en la entidad y en situaciones locales.

\section{Institucionalización de la EIB en México y la Asignatura de lengua y cultura indígena en secundaria}

En el año 2000, por primera vez desde 1929, cambió el partido gobernante en México. El presidente Vicente Fox, del Partido Acción Nacional (PAN), de derecha conservadora, se presentaba como agente de la democratización. En 2001 creó la Coordinación General de Educación Intercultural y Bilingüe (CGEIB), dependencia de la Secretaría de Educación Pública (SEP) encabezada por Sylvia Schmelkes, académica con experiencia en gestión política nacional e internacional.

La interculturalidad se proponía como un proyecto social, una postura filosófica y un ideal ético que, mediante la práctica pedagógica, transformaría la manera de concebir a los pueblos indígenas y propiciaría que toda la sociedad y que los propios indígenas se valoraran a sí mismos de manera positiva (CGEIB, 2004). La CGEIB tuvo la consigna de hacer extensiva la educación intercultural a toda la población, indígenas o no, en todos los niveles del sistema educativo. Sin embargo, los funcionarios de la institución argumentaban que en los contextos indígenas había mayor rezago y condiciones históricas de desigualdad, por lo que era más urgente atenderlos (notas personales, 2009).

Entre sus principales proyectos, la CGEIB decretó la creación de universidades y bachilleratos interculturales. Con el Programa Nacional de Educación 2000-2006 comenzó una reforma para incluir el nivel secundaria en el tramo de la educación básica; uno de sus propósitos era "enseñar para la diversidad" (SEP, 2002, p. 22). En ese marco, se proyectó extender la educación bilingüe, hasta ese momento impartida solo en primarias indígenas, a los tres grados de la secundaria. Así, se propuso la asignatura de Lengua y Cultura Indígena. El principal creador de este proyecto fue el maestro Alonso López Mar, quien tenía larga trayectoria como maestro bilingüe de náhuatl y español, y reconocido entre su gremio como intelectual y luchador de los derechos indígenas. Al formarse la CGEIB, fue comisionado desde la Dirección General de Educación Indígena (DGEI) de la SEP para fungir como primer director de la Dirección de Desarrollo de Currículum Intercultural (DDCI) en la CGEIB.

López Mar realizó gestiones para que maestros de primarias adscritas a la DGEI fueran comisionados como diseñadores y docentes de los programas de secundaria. Las autoridades de primaria en los estados no siempre estuvieron de acuerdo, y varios maestros de secundaria llegaron a mostrar desconfianza con respecto a las habilidades de los maestros de primaria para trabajar en el nivel. A pesar de las resistencias, la fuerza política y presupuestal que la CGEIB tuvo en sus primeros años, ${ }^{1}$ sumada a la reforma educativa en ciernes, logró que entre 2002 y 2006 se diseñaran programas para secundaria en 16 lenguas distintas. Entre ellos, el de Lengua y Cultura Ch'ol de Chiapas para los tres grados de secundaria.

1. De 2000 a 2004 , el gobierno federal incrementó el presupuesto educativo, "en el ciclo escolar 2003-4, México gastó en educación cinco veces más" que 23 años atrás (Muñoz, 2006, p. 269, citando a Granados, 2004). 


\section{La asignatura de Lengua y cultura $\mathrm{Ch}^{\prime}$ ol de Tabasco: vaivenes de la EIB en las reformas educativas}

Tabasco está en la zona tropical al sureste de México y colinda con el estado de Chiapas. En esa zona habitan comunidades hablantes de la lengua ch'ol. Estos poblados se fundaron como ejidos durante el siglo XX con población migrante proveniente de Chiapas que, a causa de la explotación, el despojo de tierras, la escasez de trabajo y los conflictos armados, se desplazaron para colonizar nuevas tierras y sobrevivir (Bermúdez, 1999; Alejos y Martínez, 2007; Rojas, 2019). En Tabasco, los hablantes de la lengua ch'ol fueron oficialmente reconocidos a finales del siglo XX, pues antes los hablantes de yokot'an (chontal) eran los únicos identificados como indígenas. Ambas son lenguas mayas. En el censo de 2010 se identificó el incremento de hablantes de ch'ol (Galán, 2019), aunque la lingüista Amelia Escobar afirma que la lengua se encuentra en proceso de desplazamiento y extinción acelerada. Ella señala que en las escuelas bilingües creadas en Tabasco, durante la década de 1970, el ch'ol fue relegado por el español. También considera que las políticas del lenguaje emprendidas por la CGEIB han contribuido al mantenimiento de la lengua (Escobar, 2019).

Los proyectos de la CEGIB en Tabasco comenzaron en 2004 al convocar profesionistas hablantes de ch'ol y yokot'an para crear la universidad intercultural, inaugurada en 2005. Poco después, la institución federal solicitó a la SEP del estado que comisionara maestros hablantes de esas lenguas para diseñar los programas de estudios de la asignatura de lengua y cultura indígena. En secundaria no se encontraron maestros con ese perfil, y los de primaria, hablantes de yokot'an, tuvieron dificultades para las comisiones. En diciembre de 2004,

2. Los nombres de los participantes en Tabasco han sido cambiados por pseudónimos. la maestra Elena, ${ }^{2}$ historiadora, hablante de ch'ol, recién incorporada como maestra de telesecundaria y bibliotecaria en la universidad intercultural, fue invitada por los funcionarios locales para trabajar en la asignatura de lengua y cultura ch'ol en secundaria.

La maestra relata que no sabía cuál era el proyecto, pero tuvo solo un día para decidir, y señala "no sabía escribir, ni leer en ch'ol" (Comunicación personal, 15 de enero de 2020). Aceptó, y al día siguiente estaba, junto con maestros de otros estados, en un taller organizado y financiado por la DDCI en la Ciudad de México para capacitarse en el diseño de los programas de estudio de lengua y cultura indígena en secundaria. Ahí, la maestra Elena conoció al diseñador del programa ch'ol para Chiapas, profesor de primaria y lingüista. En la plática, el maestro supo que ella no sabía leer ni escribir su lengua y le propuso escribirse correos electrónicos en ch'ol para que ella aprendiera. Elena relata que escribía como se imaginaba hasta que el maestro le dijo que no lograba entenderla, entonces programaron asesorías personalizadas y así ella aprendió a leer y escribir su propia lengua. En 2005, las autoridades de secundaria en Tabasco comisionaron a Elena para dedicarse completamente a la asignatura, y los siguientes dos años asistió a talleres sobre el diseño del programa de estudios.

Al finalizar el gobierno de Vicente Fox, durante el ciclo escolar 2005-2006, se hicieron pruebas piloto de los programas en 14 estados del país. Tabasco no participó en las pruebas porque las autoridades de secundaria en el estado aún seleccionaban docentes para la asignatura. La maestra Elena estableció como criterios: ser hablantes nativos de ch'ol; hablarlo en lugares públicos sin timidez; vivir o trabajar en comunidades de hablantes y traducir textos de español a ch'ol. Cumplieron con esos requisitos once docentes de preescolar y primaria de la DGEI, quienes tradujeron los textos de manera oral porque no sabían leer ni escribir la lengua (Comunicación personal, 21 de junio de 2021). 
De 2006 a 2012, fue presidente Felipe Calderón, también del PAN, pero con menos autoridad que Fox debido a la sospecha de fraude electoral. Ese presidente asignó mayor gasto a una política de violencia que llamó "guerra contra el narcotráfico". La educación recibió menos presupuesto, y Sylvia Schmelkes, primera coordinadora de la CGEIB, dejó el puesto en 2007. Poco después, Alonso López Mar regresó a la DGEI para jubilarse. Los funcionarios que los sustituyeron no tuvieron el mismo respaldo por parte del gobierno federal; su experiencia en la gestión de la política educativa era menor, así como su autoridad ante los funcionarios federales y estatales.

El gobierno de Calderón consolidó la Reforma Integral de la Educación Secundaria en 2006. Esa reforma ordenó incorporar contenidos sobre la diversidad cultural y lingüística del país en todas las asignaturas y grados. Eso se cumplió mínimamente en algunos de programas de estudios y libros de texto. Lo relevante para la asignatura de Lengua y Cultura fue que el plan y los programas de secundaria cambiarían para incorporarse al tramo de educación básica. La gestión política de la DDCI con otras instancias de la misma jerarquía en la SEP (Figura 1) se benefició porque la DGEI estaba obligada a facilitar las comisiones de maestros, y la Dirección de Desarrollo Curricular (DGDC) de la Subsecretaría de Educación Básica (SEB) debía incorporar la asignatura al currículum del tramo básico.

Figura 1. Jerarquías institucionales a nivel federal en 2006.

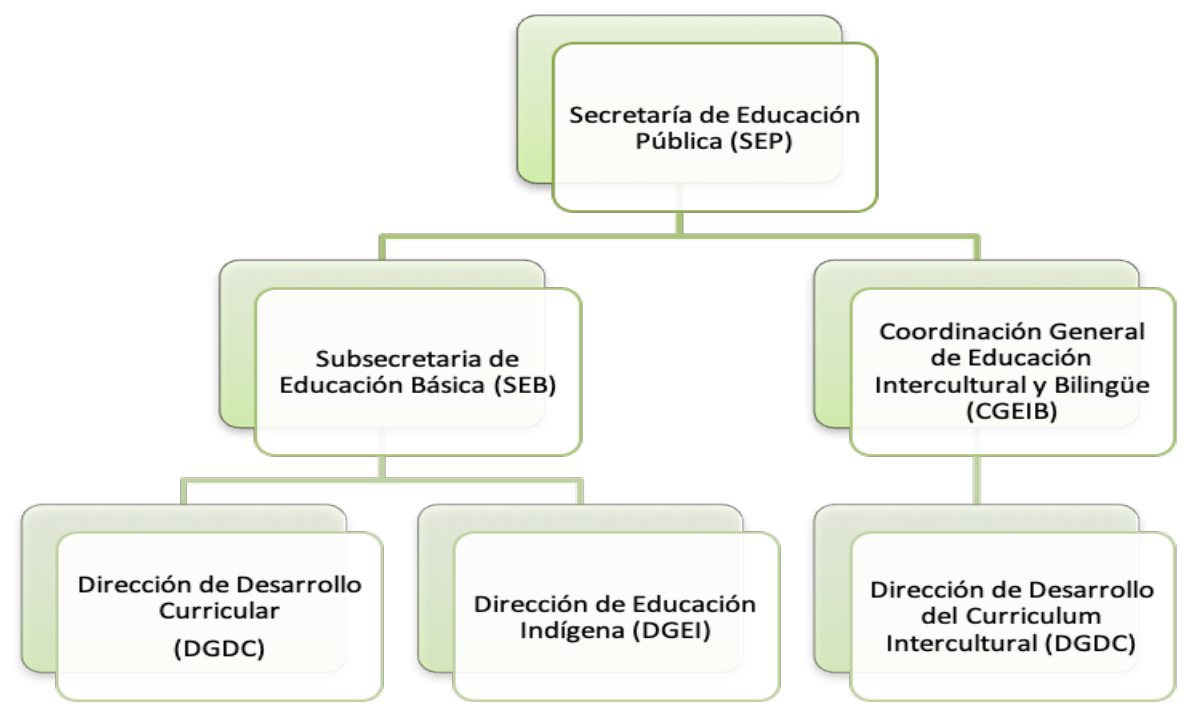

El nuevo mapa curricular de primer grado de secundaria abrió un espacio llamado "Asignatura estatal", que ofrecía campos temáticos, y cada estado podía diseñar programas de estudios según las necesidades e intereses de los estudiantes locales. La CGEIB consiguió que la asignatura de Lengua y Cultura Indígena constituyera uno de esos campos y fuera obligatoria en las localidades con $30 \%$ o más de población hablante de alguna lengua indígena ${ }^{3}$ (Diario Oficial de la Federación, DOF, 2006).

En 2007, las autoridades de Tabasco designaron al maestro Alejandro para coordinar el campo de Lengua y Cultura. Durante el ciclo escolar 2007-2008 se
3. En Durango no se cumplía con ese criterio, pero las autoridades educativas tuvieron la voluntad de crear un programa en tepehuano. 
hicieron pruebas con el programa de tercer grado diseñado para Chiapas y el programa de primero se implementó en 16 telesecundarias. Desde su ingreso, el maestro Alejandro, abogado de formación, comenzó una negociación con el área de recursos humanos de la SEB en el estado para crear plazas docentes exclusivas de la asignatura de Lengua y Cultura. Hubo mucha resistencia, pero en 2009 se consolidó el Decreto 172 (2009) de la Ley de Derecho y Cultura Indígena del estado de Tabasco y con ello se fijaron las once plazas de horasemana-mes para los maestros de ch'ol. Quienes tenían horas en preescolar y primaria pudieron simultáneamente trabajar en otras escuelas (Comunicación personal, febrero de 2011 y 15 de enero de 2020).

Durante esos años, la maestra Elena socializaba con los docentes lo aprendido en los talleres de la CGEIB y revisaba el trabajo en las escuelas. Los maestros quisieron aprender a leer y escribir su lengua y solicitaron al maestro de Chiapas que les diera talleres de gramática y lectoescritura del ch'ol. El estado no les dio presupuesto para eso, y los docentes pagaron de sus propios recursos. Al principio, se comunicaban en español durante las reuniones de trabajo, pero la maestra Elena siempre usó el ch'ol para dirigirse a ellos y poco a poco los maestros comenzaron a usar esa lengua para todas las actividades. El uso los llevó a reflexionar sobre la cantidad de palabras en español que usaban junto con el ch'ol y así trataron de usar la lengua sin interferencias. Solo se comunicaban en español cuando estaban en los talleres de la CGEIB para que los funcionarios estatales comprendieran lo que se decía (Notas de trabajo, 2010-2012 y comunicaciones personales, 2020). Con el tiempo, los maestros consideraron que debían tener un programa de estudios propio, contextualizado para Tabasco y no para Chiapas. En 2009, Elena, Alejandro y otros tres profesores comenzaron a diseñar el programa "Así somos los choles de Tabasco".

La DDCI organizaba talleres periódicamente con los equipos diseñadores de todos los estados involucrados. Como resultado, de 2002 a 2010, se llegaron a diseñar programas de estudio en 24 lenguas distintas ${ }^{4}$ para 16 estados. Se diseñaron algunos programas para los tres grados, pero en muchos de ellos solo se hicieron las pruebas piloto (Notas de trabajo, 2009-2012). Durante esos años, las negociaciones entre la DDCI con la DGDC para integrar los programas al currículum nacional tuvieron fuertes tensiones porque la DGDC había sido hasta entonces la única autoridad competente para determinar el currículum, y en la DDCI se consideraban expertos en currículum y en educación indígena. Con frecuencia se discutía la naturaleza de los programas porque cada tema se vinculaba al estudio de la lengua. Para la DGDC, ese aspecto y el diseño bilingüe les hacía ubicar la asignatura en el campo de Lenguaje y Comunicación y no en la Asignatura estatal (Notas etnográficas, 2010).

Para 2010, el equipo de Tabasco había diseñado su propio programa, un cuaderno de trabajo, una guía didáctica y materiales para el aula, y trabajaba en una antología de lecturas ch'ol-español. En 2011 se concretó la articulación de la educación básica. Los veintitrés equipos diseñadores de trece estados trabajaron para que sus programas fueran evaluados por la DGDC e integrados formalmente al catálogo de programas nacionales. La DGDC exigió que los programas cumplieran con los lineamientos curriculares (SEP, 2011), aunque en las negociaciones con la DDCI se acordó que todos los programas de lengua y cultura fueran aprobados para cumplir el marco normativo. Los lineamientos y la evaluación de los programas fueron realizados por un equipo interinstitucional conformado por la DDCI, la DGDC, la DGEI y el Instituto Nacional de Lenguas Indígenas. 
El equipo tabasqueño rediseñó su programa y lo tituló “Che'yila lakty'añ yik'oty lakcha'liya ajCHolombäla tyi Tabasco. Así es la lengua y la cultura de los CH'oles en Tabasco" (Guzmán, Euán, López y Gómez, 2012). En la Figura 2 se muestra la estructura general. Los contenidos fueron definidos por los diseñadores asesorados por la DDCI.

Figura 2. Programa de la asignatura "Che'yila lakty'añ yik'oty lakchaliya ajCHolombäla tyi Tabasco. Así es la lengua y la cultura de los CH'oles en Tabasco" (Guzmán et al., 2012, p. 24).

\begin{tabular}{|c|c|c|c|c|}
\hline \multirow[t]{2}{*}{ BLOQUES DE ESTUDIO } & \multicolumn{4}{|c|}{ PRACTICA SOCIAL DEL LENGUAJE POR ÁMBITOS } \\
\hline & $\begin{array}{l}\text { La vida familiar y } \\
\text { comunitaria }\end{array}$ & $\begin{array}{l}\text { La tradición oral, la } \\
\text { literatura y los } \\
\text { testimonios } \\
\text { históricos. }\end{array}$ & $\begin{array}{l}\text { La vida } \\
\text { intercomunitaria y } \\
\text { la relación con otros } \\
\text { pueblos }\end{array}$ & $\begin{array}{l}\text { Estudio y } \\
\text { difusión del } \\
\text { conocimiento }\end{array}$ \\
\hline $\begin{array}{l}\text { I } \\
\text { Chukoch joñoñlaj chumulñbäla tyi } \\
\text { México yä’ñäloñtyak a ¿Por qué los } \\
\text { mexicanos somos diferentes? }\end{array}$ & $*$ & & & \\
\hline $\begin{array}{l}\text { Majchoñkila tyäle bajche' lajkilal } \\
\text { xCHolombäla tyi Tabasco'. ¿Quiénes } \\
\text { y cómo somos los CHoles de } \\
\text { Tabasco?". }\end{array}$ & $\begin{array}{l}\text { Conoce los discursos } \\
\text { de los ancianos en } \\
\text { las celebraciones } \\
\text { tradicionales de la } \\
\text { comunidad. }\end{array}$ & & $\begin{array}{l}\text { Conoce los discursos } \\
\text { de los ancianos en } \\
\text { las celebraciones } \\
\text { tradicionales de la } \\
\text { comunidad. }\end{array}$ & \\
\hline $\begin{array}{l}\text { III } \\
\text { xCHolob tyälemobä tyi ixim. Los } \\
\text { CHoles hombres del maíz. }\end{array}$ & & & & $\begin{array}{l}\text { Difundir la forma de } \\
\text { organización en la } \\
\text { cosecha de maíz. }\end{array}$ \\
\hline $\begin{array}{l}\text { IV } \\
\text { Oño' cha'liyaj yik'oty oño' ty’añtyak } \\
\text { laktyaty ña'o'. } \\
\text { Tradiciones y costumbres orales del } \\
\text { pueblo CHol". }\end{array}$ & & $\begin{array}{l}\text { Narrar relatos orales } \\
\text { y escritos de la } \\
\text { lengua } \mathrm{CHol} \text {. }\end{array}$ & & \\
\hline $\begin{array}{l}\text { V } \\
\text { Ts'akejel cha'añ xCHolo'. La medicina } \\
\text { tradicional CHol. }\end{array}$ & & & & $\begin{array}{l}\text { Difundir las prácticas } \\
\text { de curaciones } \\
\text { tradicionales de } \\
\text { pueblo } \mathrm{CHol} \text {. }\end{array}$ \\
\hline
\end{tabular}

*En el estudio del primer bloque no se considera trabaja por un ámbito en específico, por lo que no se representa en el cuadro.

En el discurso, la CGEIB defendía que la asignatura incorporaría las historias de los pueblos y articularía las perspectivas de lo local con lo nacional. En esta revisión retrospectiva, observo que las orientaciones a los diseñadores no retomaron de manera crítica los temas locales ni los problematizaron con relación a lo nacional. Por ejemplo; en la Figura 3, el Bloque 1 del programa de Tabasco aborda contenidos relativos a las generalidades de los ch'oles, las lenguas y culturas mayas, pero no se abordan las historias de migración y explotación o los conflictos armados y por la tierra que provocaron el asentamiento de los ch'oles en Tabasco. En el abordaje de la medicina tradicional tampoco se dieron orientaciones para conocer y reflexionar sobre la alienación de los saberes medicinales y las consecuencias de ello. La DDCI no problematizó las cuestiones de la desigualdad y, al parecer, nadie notó esa contradicción. 
Figura 3. Bloque 1 del programa de estudios "Che'yila lakty'añ yik'oty lakcha'tiya ajCHolombäla tyi Tabasco. Así es la lengua y la cultura de los CH'oles en Tabasco" (Guzmán et al., 2012, p. 25).

\section{BLOQUE: I}

\section{CHUKOCH JOÑOÑLAJ CHUMULOÑBÄLA TYI MÉXICO YÄ'Ñ̈̈LOÑTYAKLA.} ¿POR QUÉ LOS MEXICANOS SOMOS DIFERENTES?

\section{COMPETENCIA QUE SE FAVORECE:}

Respeto y valoración de la diversidad social, étnica, cultural y lingüística del país.

\begin{tabular}{|c|c|c|}
\hline APRENDIZAJES ESPERADOS & TEMAS DE REFLEXIÓN & $\begin{array}{l}\text { PRODUCCIONES PARA EL } \\
\text { DESARROLLO DEL PROYECTO Y } \\
\text { PRODUCTO FINAL }\end{array}$ \\
\hline $\begin{array}{l}\text { Reconoce la diversidad lingüística y } \\
\text { cultural del país. } \\
\text { Identifica la región de asentamiento de la } \\
\text { cultura maya. } \\
\text { Identifica los sonidos de sus lenguas y las } \\
\text { grafías para escribirlas. } \\
\text { Conoce la influencia de la cultura y lengua } \\
\text { maya en la conformación del pueblo CHol. }\end{array}$ & $\begin{array}{l}\text { Ichumli'o', ichajpajbäjo' yik'oty ity'año' } \\
\text { xñaxañ chuñtyälo' tyi México. } \\
\text { La diversidad cultural y } \\
\text { lingüística de México. } \\
\text { Antecedentes históricos. } \\
\text { l'ñatyäñtyel bajche' yilalo', tyäle ichumli'o' } \\
\text { xMayajo'. } \\
\text { Principales características de la cultura y la } \\
\text { lengua maya y la zona geográfica de } \\
\text { influencia. } \\
\text { l'ñatyäñtyel bakibä ty'añtyak tyälemobä tyi } \\
\text { Maya. } \\
\text { El contacto entre pueblos mayas y sus } \\
\text { características comunes en la lengua y la } \\
\text { cultura. } \\
\text { Isujmilel lakty'añ CHol yik'oty kaxlañ ty'añ. } \\
\text { Che' bajche' its'ijbuñtyel, ipejkäñtyel. } \\
\text { Características de la lengua CHol y sus } \\
\text { semejanzas diferencias con el español } \\
\text { (el uso de la sexta vocal, los consonantes } \\
\text { compuestos, los consonantes glotalizados) }\end{array}$ & $\begin{array}{l}\text { Investiga, selecciona y analiza la } \\
\text { información de las diversas culturas de } \\
\text { México. } \\
\text { Rompecabezas de la república } \\
\text { mexicana para ubicar en cada estado la } \\
\text { diversidad lingüística y } \\
\text { cultural del país. } \\
\text { Mapa para ubicar las lenguas } \\
\text { mayenses. } \\
\text { Texto en donde se describan las principales } \\
\text { características culturales del pueblo maya. } \\
\text { Cuadro comparativo de palabras iguales y } \\
\text { similares de lenguas CHol y maya. } \\
\text { Borradores del tríptico retomando } \\
\text { lo aprendido en el proyecto, sobre la } \\
\text { diversidad lingüística y cultural del país. } \\
\text { Producto final: Tríptico para } \\
\text { difundir en la comunidad escolar. }\end{array}$ \\
\hline
\end{tabular}

5. Otra entidad federativa en la que se crearon plazas fijas fue el Estado de México. La asignatura se impartía de manera constante al menos en once estados (Notas de trabajo, 2011-2012).
Lo que constituyó una innovación fue el estudio de las lenguas locales en secundaria y su uso para abordar los temas. Como se aprecia en la Figura 4, los recursos didácticos usados por la maestra en el aula están completamente en lengua ch'ol, y arriba del pizarrón hay un vocabulario ilustrado de sustantivos en ch'ol. Esto significó que los estudiantes aprendieran a leer y escribir su lengua, y en algunos casos, incluso a hablarla. En 2011, Tabasco era uno de los estados con mayor estabilidad para impartir la asignatura debido al aseguramiento de las plazas docentes. ${ }^{5}$ 
Figura 4. Foto representativa de los recursos didácticos usados por los profesores de Lengua y Cultura Ch'ol para el Bloque 1 del programa de estudios.

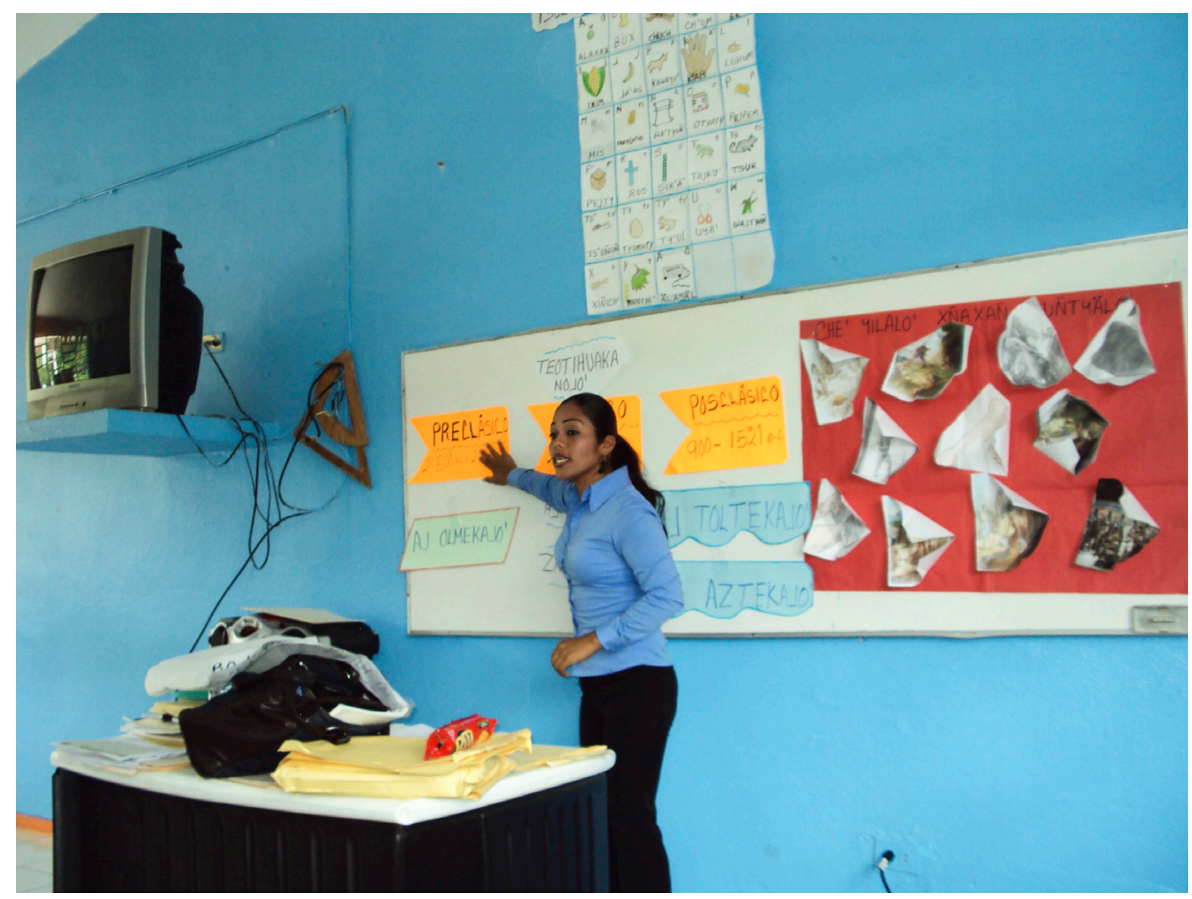

Archivo personal, 2011. Aula de Telesecundaria. Tacotalpa, Tabasco.

La presidencia de Calderón formalizó las reformas de 2006 y 2011, pero precarizó el presupuesto para cumplirlas, y la estrategia que entonces favoreció la asignatura facilitó su desaparición más tarde. Para comprenderlo es preciso observar que, en 2006, los funcionarios de la CGEIB se concentraron en fijar la obligatoriedad de la asignatura de Lengua y Cultura por número de hablantes en uno de los campos temáticos de la asignatura estatal del primer grado y esperaban negociar posteriormente los espacios curriculares para segundo y tercero. Pero nunca fue posible porque, al concluir el gobierno de Fox, disminuyó el peso político y económico de la CGEIB; además, los funcionarios que sustituyeron a Schmelkes y López Mar tenían menos condiciones a su favor. A esto se sumó que en la reforma de 2011, la EIB se consideró parte de la educación inclusiva y, como mostraré después, ese desplazamiento debilitó el discurso institucional. En 2012, el Partido Revolucionario Institucional (PRI) que había gobernado México durante el siglo XX, regresó a la presidencia con Enrique Peña Nieto, quien gobernó hasta 2018. Esta gestión comenzó otra reforma educativa para la educación básica, y la asignatura estatal desapareció de secundaria (SEP, 2016). Así, la CGEIB no logró fijar un espacio conceptual propio en el currículum de los tres grados de secundaria.

El cambio en el gobierno federal impactó en las autoridades educativas de Tabasco. En 2012, la directora de secundaria, la coordinadora estatal de la reforma y el maestro Alejandro, quienes habían impulsado fuertemente la asignatura de Lengua y Cultura $\mathrm{Ch}^{\prime} \mathrm{ol}$, fueron removidos de sus puestos. Todos los maestros que habían trabajado en oficinas de la secretaría a causa de la asignatura estatal regresaron a sus escuelas. La maestra Elena esperaba lo mismo, pero esto no ocurrió. La secretaría del estado ya no invirtió recursos para talleres, ni para que la maestra hiciera seguimiento en escuelas ni mejoras al programa, y las nuevas autoridades se llegaron a mostrar hostiles con ella, 
quizás por ser la única que quedaba de la administración anterior. En repetidas ocasiones solicitó regresar a trabajar en escuela. Un día, en 2013, la directora de secundaria en Tabasco se comprometió a reubicarla, pero al día siguiente, la directora de la DDCI envió oficios para solicitar que no la removieran, por ser una pieza clave para la asignatura (Comunicación personal, 15 de enero de 2020).

Los procesos de reforma llevan tiempo, y hasta 2014, los programas de asignatura estatal seguían en el catálogo nacional de programas de estudios, y la asignatura de ch'ol continuó impartiéndose. Entre 2012 y 2013, tres docentes de Tabasco renunciaron en busca de mayor estabilidad laboral y una maestra se jubiló.

La reforma del gobierno de Peña Nieto inició en 2014 y se consolidó en 2017. En ese marco, se pidió a la CGEIB crear el "Programa Especial de Educación Intercultural 2014-2018" (PEEI) (DOF, 2014). La institución desarrolló un diagnóstico y estrategias para fortalecer la EIB en todo el sistema educativo. Sin embargo, en ese sexenio, la CGEIB se precarizó en extremo y la reforma educativa designó mayores recursos a la evaluación de los docentes y al recién creado Programa Nacional de Inglés (PNI), que ordenó la enseñanza obligatoria del inglés en toda la educación básica.

La CEGIB elaboró el PEEI en 2014 usando los mismos conceptos que se habían usado en las reformas anteriores. El documento afirma que la EIB no es una cuestión solo ligada a los indígenas, y que la lengua es el vehículo de denominación y transmisión cultural (PEEI, 2014). Aparecen repetidamente los términos lengua materna y lenguas nacionales en el sentido de lengua indígena (como si el español no fuera también una lengua materna), lo que queda claro en tres de los seis objetivos que abordan la cuestión lingüística: Objetivo 1: Fortalecer la pertinencia cultural y lingüística en la educación básica. Objetivo 3: Fortalecer la educación superior con calidad y pertinencia lingüística. Objetivo 6: Promover el fortalecimiento, el desarrollo, la valoración, la enseñanza y la preservación de las lenguas indígenas nacionales en todo el sistema educativo nacional (PEEI, 2014).

El PNI se basa en el diagnóstico general del Plan Nacional de Desarrollo para afirmar que México enfrenta barreras que limitan su desarrollo (DOF, 2017), y asevera que el aprendizaje del inglés contribuirá al desarrollo sostenible del país. Como ampliaré en el siguiente apartado, todo esto apunta a que la semántica discursiva de la reforma es contradictoria al interior de sí misma.

En 2014, la directora del área de currículum intercultural dejó su puesto, y en 2016 el coordinador de la CGEIB fue relevado por Moisés Robles Cruz, político priísta anteriormente director general del Instituto Estatal de Educación Pública de Oaxaca. Durante su gestión en la coordinación, los recortes del personal fueron cada vez mayores y el presupuesto para los proyectos fue mínimo. De 2014 a 2019, la DDCI fue ocupada consecutivamente por dos directoras que ya tenían muy limitadas sus posibilidades para relanzar la asignatura a nivel nacional.

En 2015, era un hecho que la asignatura ni siquiera estaba mencionada en el nuevo modelo educativo. Entonces, la maestra Elena finalmente fue ubicada en una escuela telesecundaria. En 2017 comenzó a implementarse la reforma priísta y había un espacio llamado "Autonomía Curricular", en el cual los estados propondrían programas de interés local. Al parecer, la DDCI convocó 
a algunos equipos docentes para ajustar los programas de la asignatura de Lengua y Cultura Indígena e impartirla en las horas de autonomía curricular (García, 2019).6 Los maestros de Tabasco no fueron convocados; en cambio, algunos de ellos fueron asignados para apoyar actividades de lectoescritura en español en las secundarias donde trabajaban. En otras escuelas, el programa de lengua y cultura ch'ol sí continuó impartiéndose durante las horas de autonomía curricular, pero esa decisión dependió de los intereses de cada comunidad educativa y no de la gestión federal o estatal.

Recientemente, Escobar (2019) registró tres escuelas en las que se impartía la asignatura. En mis propias indagaciones, a inicios de 2020 encontré que hay seis docentes con horas fijas para impartir la asignatura de Lengua y Cultura Ch'ol; también registré un ejido donde la mayoría de los habitantes hablan esa lengua y la comunidad ha decidido mantener la asignatura en la secundaria. El maestro, quien simultáneamente es director de la primaria en la misma comunidad, se ha mantenido dispuesto a darle continuidad, aunque la asignatura no aparece en el registro de calificaciones (Comunicación personal, 14 de enero, 2020). Desafortunadamente, no he logrado regresar a la comunidad para recabar datos etnográficos que me permitan explicar esta situación.

Hasta aquí he mostrado que la EIB se ha presentado en todas las reformas y, aunque el discurso es más o menos homogéneo, las voluntades, posiciones y fuerza política de las personas y las estructuras institucionales no han podido sostenerla. Por otra parte, las conceptualizaciones de la EIB han mantenido una semántica continua pero contradictoria al interior de su propio discurso, tal como analizo en el siguiente apartado.

\section{Continuidades y contradicciones en la semántica discursiva de la EIB}

Para comprender por qué la asignatura de Lengua y Cultura tuvo tanta fuerza en Tabasco y luego fue abandonada, propongo dos vías de análisis. Primero, la manera en la que se ha evocado, el sentido semántico y las contradicciones conceptuales e ideológicas que entraña la noción de educación intercultural y bilingüe en los discursos estatales federales. Segundo, las consecuencias de eso a escala de la entidad y en situaciones locales. Mi perspectiva tiene de fondo una noción del estado7 que, acorde con Claudia Briones (2015, p. 24), se define como "formaciones pluricentradas y multidimensionales que condensan discursos y prácticas políticas de diferente tipo". Los estudios de antropología del estado observan que esas formaciones o construcciones varían según la posición de los actores en las prácticas sociales cotidianas (Adams, 2018), donde emergen relaciones, sentidos y significados en tensión constante (Das y Poole, 2008) y en las que incluso "lo local" tiene un carácter abierto e incongruente (Gupta, 2018).

Considero necesario analizar las formas que adquiere el lenguaje y la construcción del discurso común de la EIB porque las palabras pueden señalar y expresar relaciones de poder; igualmente las formas en las que se usa el lenguaje dan claves para analizar procesos y proyectos políticos del estado (Roseberry, 2007).

En este trabajo reflexiono sobre qué se hizo y qué se logró con la enunciación de tres elementos discursivos: la identificación de los sujetos a quienes se dirige la EIB, las conceptualizaciones de cultura y la educación bilingüe.
6. Por ejemplo, los 19 docentes de Lengua y Cultura Jñatjo en 38 escuelas del Estado de México impartieron la asignatura en el espacio de autonomía curricular. Ver García (2019).
7. Escribo "estado" con minúscula acorde con Abrams y Gupta (2018), para indicar que no es una entidad determinada, acabada y unificada, sino una construcción ilusoria que se antepone a múltiples y diversas formaciones de prácticas, relaciones y discursos. 
1) Los sujetos. En su discurso fundante, la CGEIB propone la interculturalidad como una educación incluyente que debe hacerse extensiva a toda la población para que la diversidad sea valorada como riqueza y la sociedad se transforme (CGEIB, 2004). Se afirma que la desigualdad educativa de los pueblos indígenas -tanto en nivel de escolaridad como en índices de rendimiento- se debe a dos asimetrías: "la asimetría valorativa [...] [que es] la valoración de la cultura propia, la autoestima cultural, la necesidad de creer en lo que se es y de reconocerse creador de cultura desde el espacio particular" (CGEIB, 2004, p. 38). Según el texto, esa asimetría es producto de la discriminación, la subordinación y el racismo sufrido e internalizado en los propios indígenas y en la sociedad en general, que provoca que las lenguas y culturas indígenas no sean valoradas de manera positiva por sus propios creadores. La "asimetría escolar [...] [que] se refiere al carácter monocultural y monolingüe de los sistemas nacionales que han implantado un modelo de escuela que ignora las necesidades particulares de cada contexto cultural y lingüístico" (CEGIB, 2004, p. 39).

En continuidad con ese discurso, la introducción del libro que presenta el desarrollo curricular de la asignatura de Lengua y Cultura Indígena argumenta que "la mala calidad de la educación, los altos índices de deserción y repetición, falta de cobertura y acceso, entre otros" se deben a "la falta de pertinencia étnica, cultural y lingüística de la educación" (Gallardo, 2013, p. 15, citando a Schmelkes, 2009) y apunta: “Que [una escuela] esté 'bien' significa cosas distintas para la clase dirigente, la clase media mestiza, la clase media indígena, las clases pobres mestizas e indígenas, etcétera" (Gallardo, 2013, p. 20).

Estos discursos entrañan una contradicción con el mandato de extender la interculturalidad a toda la población. ¿Por qué la CGEIB no propuso un espacio curricular en el cual también los estudiantes de secundaria no indígenas conocieran y valoraran positivamente la diversidad lingüística y cultural, donde se reconocieran creadores de cultura? Considero que una parte de la respuesta se encuentra en la categorización de la población implícita en el argumento de las asimetrías. Mientras los indígenas se conciben como personas con baja autoestima cultural y con singularidades que los hacen necesitar esa política educativa, no es claro en esos discursos, cómo se concibe a los que no se consideran indígenas.

En lectura de las clases sociales, cabe preguntarse ¿cuál es la comprensión de la sociedad al clasificarla en clase dirigente, clase media mestiza, clase media indígena, clases pobres mestizas e indígenas, etcétera? De acuerdo con algunos estudios sobre la identificación social (López y Acevedo, 2018) y el discurso (Zavala y Back, 2017), la enunciación de personas o grupos en los discursos estatales constituye una práctica discursiva que alude a una historia de las categorías y es una acción social. Hacer la clasificación justifica el argumento de las asimetrías y de las necesidades educativas de grupos diferenciados. La contradicción está en que el mismo texto arguye que la asignatura de Lengua y Cultura se corresponde con las expectativas de toda la población indígena, dando por hecho que todos tienen los mismos intereses y expectativas, que son un grupo homogéneo y no pueblos con muy diversas historias.

En la reforma de 2011, la educación intercultural se ubicó como parte de la educación inclusiva dirigida a indígenas y estudiantes con discapacidades cognitiva, física, mental o sensorial. El discurso estatal enfatiza que esa propuesta "se ocupa de reducir al máximo la desigualdad del acceso a las oportunidades y evita los distintos tipos de discriminación" (DOF, 2011). Aquí, la noción de 
diversidad y de los sujetos no se asocia a lo cultural sino a la discriminación y la desigualdad.

En la reforma de 2014, la CGEIB señaló que la interculturalidad no es una medida compensatoria, sino una alternativa para mejorar la calidad educativa de los indígenas, afrodescendientes y migrantes, así como para el resto de la población (DOF, 2014) y criticó que en la educación se fomente la idea de una población mestiza y homogénea. Aunque el discurso es más crítico, nuevamente considera que los sujetos educativos de la EIB son grupos definidos homogéneamente.

De acuerdo con algunos estudios sobre la alteridad (Araujo, 2015; Briones, 2015, López y Acevedo, 2018), ese tipo de perspectivas y las políticas derivadas de ella conllevan el riesgo de comprender la sociedad a partir de una simplificación de las diferencias entre sujetos y grupos. Paradójicamente, así se pueden suprimir las historias e invisibilizar los contextos y los procesos en los que actores diferenciados comparten algo común. Aunque parezca extremo, cabe cuestionar cómo las ideas racistas y clasistas en México podrían alojarse sutilmente en los discursos políticos diferenciadores como el de la interculturalidad institucional y así mantener la EIB solo para sujetos categorizados, marcados por singularidades como la lengua y que en el discurso institucional se vinculan con ideologías sobre el estatus de clase y orígenes étnicos, que aluden a la raza de las personas.

2) El concepto de cultura. El discurso de la EIB vincula directamente a los indígenas con la cultura. En el mismo texto sobre desarrollo curricular, se afirma: "La diversidad en los países latinoamericanos es producto de los procesos de colonización y mestizaje que no han podido ser resueltos en la construcción de una identidad nacional homogénea" (Gallardo, 2013, p. 17). Así se argumenta que "el Estado-nación actual intenta responder [...] a la reivindicación de la identidad mexicana desde su diversidad cultural, étnica y lingüística" (Gallardo, 2013, p. 17). En estas declaraciones hay una perspectiva dicotómica de la diversidad como resultado del contacto y la mezcla entre dos grupos homogéneos; los colonizadores europeos y los indígenas.

El concepto de cultura subyacente no contempla que entre las personas consideradas de un mismo grupo existen diferencias que pueden denominarse culturales (Erickson, 2011, p. 28). En los contenidos de la asignatura se observa que, al igual que en otros países de Latinoamérica, la EIB propone la valoración y el reconocimiento de la diversidad cultural como riqueza sin aludir a las causas que han generado la inequidad (Hecht, García, Enriz y Diez, 2015). De acuerdo con Erickson (2011), el discurso de la valoración no resuelve las asimetrías ni las diferencias sociales porque estas preexisten a lo cultural:

El conflicto sobre la diferencia cultural no es tanto por la diferencia en sí misma, sino por la carga política y el simbolismo de la diferencia. [Retomando a McDermott y Barth]... la diferencia cultural no causa el conflicto en la sociedad o en la interacción social inmediata, sino que las razones del conflicto ya existen en la sociedad, por ejemplo, en las diferencias de poder o en los intereses de grupos, entonces la diferencia cultural se vuelve una fuente de conflicto. (Erickson, 2011, p. 29)

La definición de lo indígena, lo étnico y lo cultural propicia, en palabras de Alejandro Araujo (2015, p. 169), "un retorno o fortalecimiento de una concepción genealógica de la nación, quizá incluso racialista". Este tipo de discurso que busca reivindicar la representación y la historia de ciertos grupos 
"naturaliza con fuerza las divisiones y las diferencias que conforman la nación y sustancializa las identidades sociales; aunque en teoría, acepte las diferencias dentro de las naciones como nación multi o pluricultural" (Araujo, 2015, p. 169). Desde una perspectiva histórica, la noción de interculturalidad mantiene una continuidad semántica con el indigenismo de Aguirre Beltrán acerca de las relaciones entre dos grupos culturales distintos. Se enfoca en el simbolismo de las diferencias radicales e invisibiliza los procesos que los grupos comparten.

Categorizar a los indígenas como los sujetos que necesitan la asignatura responde al concepto de cultura como "el fruto histórico de la dinámica social [...] desde su origen hasta el tiempo actual" (Gallardo, Hernández y Santos, 2013, p. 65). Así, la cultura es un objeto complejo pero determinado que se puede delimitar mediante la historia, la cosmovisión y las formas de construir conocimiento. Desde mi punto de vista, una de las mayores trampas ideológicas y discursivas de la interculturalidad en todas las reformas analizadas es continuar con la semántica de las culturas como esencialización de conjuntos estáticos y no como procesos dinámicos y multiformes de la historia en curso.

3) El concepto de educación bilingüe. La EIB en México abreva de los movimientos sociales que denunciaron la extinción de las lenguas atribuyéndola a la asimilación del indigenismo y la simulación de la educación bilingüe del siglo XX. La CGEIB planteó que revitalizar las lenguas indígenas en el currículum tendría el mismo efecto en las culturas correspondientes. El discurso institucional entraña algunas contradicciones, pues asume que una lengua corresponde directamente a un grupo social delimitado, una cultura, una cosmovisión y un pensamiento. Esa vinculación directa es lo que se enuncia en el siguiente fragmento como "identidad étnica":

La finalidad de esta asignatura es que los jóvenes en contextos indígenas, sean hablantes o no de una lengua originaria, puedan conocer, reconocer y valorar su inserción y participación en la cultura oral y escrita de una lengua originaria desde la cosmovisión que le da sentido [...] además de que fortalezcan su identidad étnica y lingüística, así como su sentido de pertenencia a una comunidad y una región con referentes culturales comunes al conocer los significados del pensamiento de su pueblo sobre la vida y el mundo, de manera que valoren la riqueza cultural y lingüística de la región multicultural donde viven. (Gallardo, 2013, p. 18 citando a SEP 2009)

Aquí, la asociación social y cultural está directamente relacionada con la lengua y sin considerar que "no todos los hablantes de una lengua comparten los mismos valores de vida" (Erickson, 2011, p. 28) y que en ningún territorio "se da una correspondencia exacta entre lengua y adscripción 'étnica'. [...] [ya que hay otros elementos sociales], más que la lengua que explican el sentimiento de solidaridad de un grupo" (Zabaltza, 2006, p. 235). La propuesta de diseñar los contenidos curriculares a partir de lo que se identifica como significado cultural de las prácticas del lenguaje corre el riesgo de esencializar la cultura, la identidad y las prácticas lingüísticas, porque no considera que en un mismo grupo de hablantes hay diversidad de repertorios culturales, lingüísticos y comunicativos con los que dotan de sentido sus prácticas sociales cotidianas.

Otro riesgo está en que las opiniones que se tienen sobre la lengua y sus variedades suelen evocar de manera implícita características raciales, no necesariamente biológicas sino ideológicas (Zavala y Back, 2017). Cabe cuestionar si en la asociación entre lengua-cultura-etnicidad subyacen ideologías raciales. Si la 
EIB buscaba aumentar la autoestima y el orgullo de los indígenas por hablar sus lenguas, ¿por qué hacer obligatoria la asignatura en poblaciones donde la vitalidad lingüística es mayor y no en donde el uso y las valoraciones por hablarlas están menoscabadas? Por una parte, el número de hablantes de una lengua registrado en los censos es un dato parcialmente objetivo, porque los prejuicios lingüísticos pueden llevar a las personas a mentir. Una persona con valoraciones desfavorables hacia la lengua de su comunidad podría declarar que habla español por ser la lengua prestigiada. En cambio, los que quieren afirmar su pertenencia a la comunidad declaran que hablan la lengua local (Moreno, 2016). Por lo tanto, incrementar el prestigio de ciertas lenguas es más urgente en localidades con "menos" hablantes.

Por otra parte, esa política se basó en una "geografía estatal de inclusión y exclusión" (Briones, 2015, p. 25). La continuidad semántica que construye simbólicamente la categorización de los indígenas como grupos homogéneos, excluidos y rezagados requiere de marcas evidentes que los delimiten. Así, la lengua se convierte en un operador que los ubica en regiones específicas. Esa lógica espacial diferenciada promovió una dinámica contradictoria con el objetivo de extender la EIB a toda la población e invisibilizó la enorme diversidad de las sociedades en otras escuelas del país.

Otra contradicción está en la idealización de la educación bilingüe. En todos los sistemas escolares bilingües una lengua es dominante, incluso si los cursos están equilibrados, ya que en el entorno exterior, la lengua dominante se impone (Moreno, 2016). En la reforma 2012-2018, el PEEI señalaba que la diversidad lingüística del país es una riqueza y un patrimonio de la humanidad que está en riesgo de desaparecer y por ello es necesario revitalizar, desarrollar y fortalecer las lenguas indígenas (PEEI, 2014, p. 64). Simultáneamente, el Programa Nacional de Inglés (PNI) afirmaba:

Si queremos que [niños, niñas y jóvenes] tengan la oportunidad de desarrollar sus talentos y capacidades no pueden quedarse sin aprender el lenguaje que habla el mundo, saber hablar inglés es fundamental, el inglés es la lengua que las personas de los orígenes más diversos pueden dialogar y entenderse, por lo que impulsar que los estudiantes de México lo aprendan significa abrirles la puerta hacia nuevas oportunidades. (DOF, 2017)

En este discurso, la diversidad lingüística del país no es equivalente a la diversidad que se abre si se aprende inglés. El PEEI propone desarrollar "las lenguas", mientras el PNI se refiere a los talentos y capacidades de los hablantes. Las "lenguas indígenas" se presentan como objetos patrimoniales, como piezas de museo; en cambio, el inglés se concibe como una herramienta para alcanzar el desarrollo. La ideologización de estas lenguas es resultado de la categorización de los hablantes y de la asociación directa entre lengua-cultura-pensamiento y etnicidad. Esta perspectiva es constante en las reformas, y en ninguna de ellas se consideran las situaciones en que estudiantes y maestros hablan más de dos lenguas llamadas indígenas, español e inglés, además de la movilidad, las comunicaciones digitales y la interacción cotidiana que plantean situaciones multilingües.

Ciertos lingüistas proponen que toda la educación escolar debería ser en las lenguas minorizadas (Moreno, 2016), pero en la realidad de México no alcanzan las voluntades, los recursos y, en ocasiones, ni siquiera los intereses de los hablantes. Ante tales desafíos, entre otros, se encuentran las políticas de educación y lenguaje en México. 


\section{Efectos del discurso federal en lo estatal y lo local}

Finalmente, para reflexionar sobre las consecuencias de las contradicciones discursivas en las escalas estatal y local, me baso en las acciones, prácticas y formas de participación que, según Rockwell, "en realidad resultan de complejos reacomodos entre poderes locales y centrales. Presuponen trabajos en los que participan grupos sociales con intereses y proyectos a menudo contrapuestos. Su desenlace es imprevisible" (2007, p. 12).

De los 16 estados en los que se trabajó la asignatura, Tabasco fue uno con mayores condiciones de estabilidad. Los discursos federales de la CGEIB abrieron un margen para las iniciativas estatales y personales. Eso se observa en la iniciativa personal del coordinador de la asignatura para fijar las plazas docentes; eso fue producto de la voluntad personal. Aunque las acciones de las autoridades de Tabasco sí eran contingentes al discurso federal, así el impulso de la asignatura de Lengua y Cultura Ch'ol se debió a la presión y presencia discursiva de la CGEIB, sumadas a la apropiación de los funcionarios de ese momento. En la reforma de 2011, los mismos términos discursivos, como educación incluyente, dotados con nuevos sentidos, derivaron en un discurso que a partir de 2012 fue cada vez más ambivalente.

El debilitamiento de la Coordinación provocó que la asignatura se desatendiera en la entidad. La contradicción entre la existencia del Programa Especial de Educación Intercultural (2014) y el Programa Nacional de Inglés (2017), sumada a la incertidumbre acerca de si el gobierno federal continuaría con la asignatura, provocaron un práctica contenciosa en la que la CGEIB gestionaba para que la maestra Elena se mantuviera como encargada, pero las autoridades locales no permitían que llevara adelante actividades relativas a la asignatura y tampoco la dejaban regresar a una escuela.

El resto de los docentes orientaron sus acciones principalmente hacia los hablantes de lengua ch'ol, demostrando así que para ellos el sentido de la EIB implicaba desarrollar la lectoescritura en su lengua, crear materiales didácticos por su cuenta y usar su lengua en lugar del español en los espacios de trabajo.

Para los maestros, la asignatura representó, primero, una oportunidad de tener un ingreso extra. Posteriormente, al desarrollar prácticas letradas en ch'ol y adquirir experiencia docente en secundarias, dos profesores hicieron el examen para obtener una plaza en telesecundarias con un ingreso más alto y renunciaron a las horas de la asignatura. Hasta 2019, seis maestros tienen las horas fijas para la asignatura y las cumplían impartiéndola como el caso registrado. Esto significa que un indicio de la asignatura federal se mantiene solo gracias a una apropiación emprendida a escala local.

En las comunidades educativas hubo consecuencias importantes. Antes de implementar la asignatura, algunos docentes de las secundarias prohibían a los estudiantes usar el ch'ol en la escuela y, al llegar los profesores de Lengua y Cultura, esas actitudes fueron cambiando, pues los maestros usaban todo el tiempo el ch'ol con los estudiantes y en la clase. Además, la maestra Elena visitaba las escuelas para dar talleres a todos los maestros y directores para que conocieran el sentido de la asignatura, y también realizó estos talleres, llamados de sensibilización, con las familias. En algunas comunidades, como La Raya Zaragoza, las familias comentaron que al tener que apoyar a sus hijos en las tareas y actividades escolares abiertas a la comunidad, habían usado el ch'ol de manera más constante (Comunicaciones personales, 2020). 
Entre 2010 y 2012, varias comunidades hicieron solicitudes a la dirección de secundarias para que se impartiera la asignatura, pero el cambio de gobierno estaba cerca y las autoridades del estado argumentaron que no tenían dinero para pagar más horas de Lengua y Cultura Ch'ol. La maestra Elena relata que en algunas reuniones comunitarias las mujeres le han preguntado si se impartirá de nuevo la asignatura y señalan que necesitan que sus hijos o ellas mismas puedan leer y escribir en ch'ol para escribir los documentos que les solicitan en varios programas gubernamentales. La maestra Elena y los otros profesores se han convertido en ayudantes de tareas escolares, escribanos y lectores de distintos mensajes en ch'ol durante actividades comunitarias. Para 2021, varios de los primeros estudiantes que cursaron la asignatura concluyen sus estudios en la Universidad Intercultural de Tabasco y han compartido con la maestra Elena que pueden presentar sus trabajos universitarios escritos en ch'ol gracias a lo que aprendieron en secundaria (Comunicaciones personales, 2020).

\section{Reflexiones finales}

Con el ejemplo de la asignatura de Lengua y Cultura muestro que la EIB en México ha tenido un constante vaivén, ya que, mientras una de sus dependencias se dedicó a hacer propuestas de educación intercultural y bilingüe, la legislación de cada reforma se dedicó a trabar esas propuestas. También he mostrado el carácter ambivalente de la EIB.

Primero, porque la categorización de los destinatarios a partir de conceptualizaciones añejas de lengua y cultura ha desencadenado políticas limitadas y contradictorias con el objetivo de extender el enfoque intercultural a toda la población. Las políticas educativas no reconocen los repertorios culturales individuales que dotan a las personas de habilidades para manejarse de manera adecuada en situaciones multiculturales, multilingües, y lo que es más grave es que este no reconocimiento conduce a la creación de estereotipos de la cultura y de las personas (Erickson, 2011). Tal como ha ocurrido con la categorización de indígenas dirigida a personas y lenguas, con la consecuencia de que la EIB no ha logrado que la población general cambiara sus percepciones sobre la diversidad ni aumente el prestigio de las lenguas. Como señala Rockwell (2015), la educación intercultural perdió fuerza porque decayó en su dimensión analítica y se convirtió un discurso prescriptivo ambiguo.

Segundo, porque como se observó en el caso de Tabasco, el discurso estatal generó por unos años condiciones de estabilidad para esta asignatura en secundaria que, de haber continuado, probablemente las autoridades locales habrían negociado a nivel local la impartición de segundo y tercer grado y los maestros habrían complejizado los contenidos de los programas. Además, hubo un incremento en el uso y una reflexión metalingüística por parte de las comunidades educativas con respecto al ch'ol. Los datos sobre el impacto local de la asignatura necesitan un estudio más profundo, que retome las experiencias de los maestros, los estudiantes y las familias.

Finalmente, este trabajo no pretende calificar las acciones de la EIB como buenas o malas. La intención es abonar desde una perspectiva etnográfica a la comprensión de los procesos en los que está inserto su discurso y los que este a su vez desencadena, con el fin de dinamizar la discusión sobre las conceptualizaciones que se usan en la política de la EIB y provocar la reflexión acerca de la educación bilingüe en la secundaria mexicana. 


\section{Financiamiento}

Con apoyo parcial del Proyecto Conacyt A1-S-52363. 2019-2022. "Incidencia de políticas educativas y modelos pedagógicos en la garantía de equidad e inclusión educativa”. Fondo Sectorial de Investigación para la Educación. México.

\section{Agradecimientos}

Agradezco a los maestros de Tabasco, especialmente a la maestra Elena, por compartir sus experiencias y reflexiones. También a las evaluadoras de este artículo, por sus observaciones. 


\section{Q Referencias bibliográficas}

" Abrams, P. (2018). Notas sobre la dificultad de estudiar el estado. En Antropología del estado (pp. 17-70). Ciudad de México: Fondo de Cultura Económica.

» Aguirre Beltrán, G. (1991-1955). Obra antropológica IX. Regiones de refugio. México, DF: Universidad Veracruzana-Instituto Nacional Indigenista.

»Alejos, G. J. y Martínez, S. E. (2007). Choles. México, DF: Comisión Nacional para el Desarrollo de los Pueblos Indígenas.

» Araujo, P. A. (2015). Regímenes de autoridad y alteridades nacionales. Notas en torno al "lugar" de "lo indígena" en la antropología mexicana. Ulúa, 25, 159-194. Recuperado de https://ulua.uv.mx/index.php/ulua/article/view/1936/pdf_272

» Bermúdez, M. J. (1999). Antigua palabra narrativa chol. México, DF: UNICACH; Plaza y Valdés.

» Briones, C. (2015). Introducción. Madejas de alteridad, entramados de Estados-nación: diseños y telares de ayer y hoy en América Latina. En D. Gleizer y P. López Caballero (Coords.). Nación y alteridad. Mestizos, indígenas y extranjeros en el proceso de formación nacional (pp. 17-65). México, DF: Universidad Autónoma Metropolitana-Cuajimalpa-Ediciones EyC.

»Coordinación General de Educación Intercultural y Bilingüe (CGEIB) (2004). Políticas y fundamentos de la educación intercultural bilingüe en México. México, DF: SEP-CGEIB.

»Das, V. y Poole, D. (2008). El estado y sus márgenes. Etnografías comparadas. Cuadernos de Antropología social, 27, 19-52. Recuperado de https://www.redalyc.org/ $\mathrm{pdf} / 1809 / 180913917002 . \mathrm{pdf}$

"Diario Oficial de la Federación (DOF) (2006). Acuerdo 384 por el que se establece el nuevo Plan y Programas de Estudio para Educación Secundaria. Recuperado de http://dof.gob. $\mathrm{mx} /$ nota_detalle.php?codigo $=4915713 \&$ fecha $=26 / 05 / 2006$

"DOF (2011). Acuerdo 592, Plan de Estudios 2011. Educación Básica, Sección VII. Recuperado de http://dof.gob.mx/nota_detalle.php?codigo=5205518\&fecha=19/08/2011

"DOF (2014). Programa especial de educación intercultural 2014-2018. Recuperado de https://dof.gob.mx/nota_detalle.php?codigo=5342484\&fecha=28/04/2014

"DOF (2017). Acuerdo número 26/12/17 por el que se establecen las reglas de Operación del Programa Nacional de Inglés para el ejercicio fiscal 2018. Recuperado de https://dof.gob. $\mathrm{mx} /$ nota_detalle.php? codigo $=5509746 \mathrm{Efech} a=29 / 12 / 2017$

»Erickson, F. (2011). Culture. En B. A. U. Levinson y M. Pollock (Eds.). A Companion to the Anthropology of Education (pp. 25-33). Malden: Wiley-Blackwell.

»Escobar, P. A. (2019). Consideraciones sobre el desplazamiento de la lengua ch'ol en Tabasco. Ruta Antropológica. Revista electrónica, 6(9), 104-135. Recuperado de http://www. posgrado.unam.mx/antropologia/revista/RUTA9.pdf

" Galán, L. F. J. (2019). Registro censal sobres los ch'oles de Tabasco a inicios del siglo XXI: Educación superior y rezago de una universidad cultural. Ruta Antropológica. Revista electrónica, 6(9), 46-73. Recuperado de http://www.posgrado.unam.mx/antropologia/ revista/RUTA9.pdf

" Gallardo, G. A. L. (2013). Introducción. En Desarrollo curricular de la Asignatura de Lengua y Cultura Indígena para la educación secundaria en México (pp. 13-59). México, DF: SEPCGEIB. 
» Gallardo, G. A. L., Hernández, M. V. y Santos, C. T. (2013). Claves para el diseño de los programas de estudio de la ALCIES: Análisis cultural, punto nodal y comunalidad. En Desarrollo curricular de la Asignatura de Lengua y Cultura Indígena para la educación secundaria en México (pp. 61-84). México, DF: SEP-CGEIB.

» García, T. A. K. (2019). El desarrollo del currículum intercultural para secundaria en México y la participación de los docentes mazahua. Memoria del XV Congreso Nacional de Investigación Educativa-COMIE. Recuperado de http://www.comie.org.mx/congreso/memoriaelectronica/v15/doc/3035.pdf

»Gupta, A. (2018). Fronteras borrosas: el discurso de la corrupción, la cultura de la política y el estado imaginado. En P. Abrams, A. Gupta y T. Mitchell. Antropología del estado (pp. 17-70). Ciudad de México: Fondo de Cultura Económica.

» Guzmán, L. H., Euán, C. M. A., Díaz, L. B., López, J. M. I. y Gómez, J. P. (2012). Che’yila lakty'añ yik'oty lakcha'liya ajCHolombäla tyi Tabasco. Así es la lengua y la cultura de los CHoles en Tabasco. Villa Hermosa: Secretaría de Educación del Estado de Tabasco.

» Hecht, A. C., García, P. M., Enriz, N. y Diez, M. L. (2015). Interculturalidad y educación en la Argentina. Discusiones en torno a un concepto polisémico. En G. Novaro, A. Padawer y A. C. Hecht (Coords.). Educación, pueblos indígenas y migrantes: reflexiones desde México, Brasil, Bolivia, Argentina y España (pp. 43-64). Buenos Aires: Biblos.

» López, C. P. y Acevedo-Rodrigo, A. (Eds.) (2018) Introduction: Why Beyond Alterity? En Beyond Alterity. Destabilizing the Indigenous Other in Mexico (pp. 3-28). Tucson: The University of Arizona Press.

» Moreno, C. J. C. (2016). La dignidad e igualdad de las lenguas. Madrid: Alianza.

» Muñoz, C. H. (2006). La reorganización intercultural de la Educación Escolar indígena de México. En C. H. Muñoz (Coord.). Lenguas y educación en fenómenos multiculturales (pp. 263-296). México, DF: Universidad Pedagógica Nacional y Universidad Autónoma Metropolitana-Iztapalapa.

»Programa Especial de Educación Intercultural 2014-2018 (PEEI) (2014). México, DF: SEPCGEIB.

» Rojas Lozano V. R. (2019). Los ch'oles de Tabasco. La reconfiguración histórica y cultural de una región. Ruta Antropológica. Revista electrónica, 6(9), 11-45. Recuperado de http:// www.posgrado.unam.mx/antropologia/revista/RUTA9.pdf

»Rockwell, E. (2007). Hacer escuela, hacer estado. La educación posrevolucionaria vista desde Tlaxcala. México, DF: El Colegio de Michocán; Centro de Investigaciones y Estudios Superiores en Antropología Social; Centro de Investigación y Estudios Avanzados.

» Rockwell, E. (2015). Conversaciones en torno a la educación con pueblos indígenas/migrantes. En G. Novaro, A. Padawer y A. C. Hecht (Coords.). Educación, pueblos indígenas y migrantes: reflexiones desde México, Brasil, Bolivia, Argentina y España (pp. 11-42). Buenos Aires: Biblos.

» Roseberry, W. (2007). Hegemonía y el lenguaje de la controversia. En M. L. Lagos y P. CaIla (Comps.). Cuaderno de Futuro No. 23. Antropología del estado, dominación y prácticas contestatarias en América Latina (pp. 117-139). La Paz: Informe Nacional sobre Desarrollo Humano del Programa de las Naciones Unidas para el Desarrollo.

»Secretaría de Educación Pública (2002). Documento Base. Reforma Integral de la Educación Secundaria. Recuperado de https://coleccion.siaeducacion.org/sites/default/files/ files/reformas_secundaria.pdf

»SEP (2011). Lineamientos para el diseño de los programas de estudio correspondientes a la asignatura estatal de secundaria. México, DF: SEP. 
"SEP (2016). Propuesta curricular para la educación obligatoria. Ciudad de México: SEP. Recuperado de https://www.gob.mx/cms/uploads/docs/Propuesta-Curricular-baja.pdf

»Zabaltza, P. N. X. (2006). Historia de las lenguas y los nacionalismos. Barcelona: Gedisa.

»Zavala, V. y Back, M. (2017). Introducción. En V. Zavala (Ed.). Racismo y lenguaje (pp. 1138). Lima: Pontificia Universidad Católica del Perú.

\section{Otras fuentes consultadas}

》Decreto 172. (2009). Ley de derechos y cultura indígena del estado de Tabasco https://sic. cultura.gob.mx/documentos/1751.pdf 
